\title{
Effect of Oxides and Carbonate on the Reaction of Hematite and Graphite Mixture Obtained by the Mechanical Milling
}

\author{
Yoshiaki KASHIWAYA, ${ }^{1)}$ Ryousuke SUZUKI') and Kuniyoshi ISHII ${ }^{3)}$ \\ 1) Formerly Graduate School of Engineering, Hokkaido University. Now at Department of Energy Science and Technology, \\ Kyoto university, Yoshida Honmachi, Sakyo-ku, Kyoto, 606-8501 Japan. E-mail: Kashiwaya@namihei.mtl.kyoto-u.ac.jp \\ 2) Formerly, Graduate School of Engineering, Hokkaido University. Now at Hokkai Iron and Coke Co. \\ 3) Professor Emeritus, Hokkaido University.
}

(Received on January 24, 2011; accepted on February 16, 2011)

\begin{abstract}
Effects of oxides $\left(\mathrm{SiO}_{2}\right.$ and $\left.\mathrm{Al}_{2} \mathrm{O}_{3}\right)$ and Carbonate $\left(\mathrm{CaCO}_{3}\right)$ on the reaction of hematite and carbon obtained by the mechanical milling were studied. The content of the additives were 3 mass $\%$. The hematite contained the oxide or carbonate was mixed with graphite, and the ratio of hematite to carbon was 80 to 20. Ball milling (alumina ball and vessel) was carried out for $24 \mathrm{~h}$ under an argon atmosphere. The reaction rates were measured by TG-DTA and examined the effects of oxides and carbonate on the reaction rate.

The main peak of reaction rate, which corresponds to the successive reaction of $\mathrm{Fe}_{3} \mathrm{O}_{4}-\mathrm{FeO}-\mathrm{Fe}$ reduction, was located at $850^{\circ} \mathrm{C}$ for no-addition sample. When 3 mass $\% \mathrm{Al}_{2} \mathrm{O}_{3}$ was added to the mixture of hematite and carbon, the temperature of main peak did not change. It was considered that since the vessel and balls were also made of alumina, the effect of alumina already existed in the no-addition sample. When 3 mass $\% \mathrm{SiO}_{2}$ (reagent grade) was added to the mixture, the temperature of main peak was $1000^{\circ} \mathrm{C}$, which meant the retardation effect on the hematite and carbon reaction. On the other hand, 3 mass $\% \mathrm{CaCO}_{3}$ addition promoted the reaction and the main peak was $790^{\circ} \mathrm{C}$, which was about $60^{\circ} \mathrm{C}$ lower than that of no-addition. Using the results of quartz and $\mathrm{CaO}$ addition, the reaction mechanisms for the retardation effect of $\mathrm{SiO}_{2}$ and the acceleration effect of $\mathrm{CaCO}_{3}$ were considered.
\end{abstract}

KEY WORDS: mechanical milling; effect of mineral matter; thermodynamic coupling.

\section{Introduction}

In the previous study, the mechanical activation on the mixture of hematite and carbon has been studied by authors. $^{1-4)}$ The reaction of the mixture obtained by the ball mill showed a quit high reaction rate. In addition, the reaction temperature decreased with the increase of milling time, which meant the decrease of fuel rate of blast furnace (BF) operation, when the function of decreasing reaction temperature can be applied to the burden of BF. The theoretical explanation for the lower fuel rate can perform by using the Rist model. Figure 1 shows the example of Rist diagram. The slope of the operation line (EA) in the Rist diagram means the ratio of $\mathrm{C} / \mathrm{Fe}$ which corresponds to the fuel rate (kg-coke/ton-pig). The line EA is written by the condition at which the temperature of reserve zone is $1000^{\circ} \mathrm{C}$, while the line moves toward the EA' when the temperature of reserve zone decreases to $800^{\circ} \mathrm{C}$, because the $\mathrm{W}$ point related to the $\mathrm{Fe}-\mathrm{FeO}$ equilibrium is changed to the lower gas composition $\left(\mathrm{CO} /\left(\mathrm{CO}+\mathrm{CO}_{2}\right)\right)$ as shown in Fig. 1.

In Japan, about 100 million tons of crude steel are produced in every year. The energy for the production of iron is significantly large and about $12 \%$ to the total energy consumption in Japan. Most of pig iron is made by blast furnace in Japan, and in the view point of the productivity and the efficiency for the reactor of iron production, blast furnace is

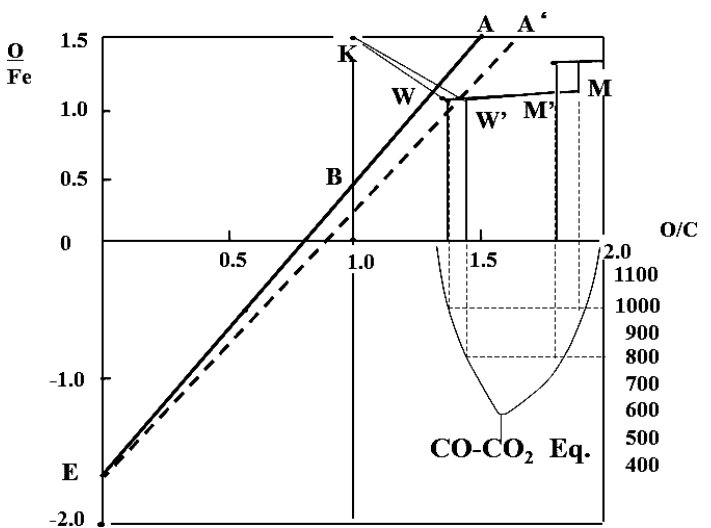

Fig. 1. Change of RIST diagram when the temperature of reserve zone decreases from $1000^{\circ} \mathrm{C}$ to $800^{\circ} \mathrm{C}$.

highest. However, such a blast furnace has further possibility for the increase of the efficiency. Recently, it was reported that the iron ore-carbon composite pellet has a high reaction rate and a low reaction temperature. The authors have explained the mechanism of acceleration using the thermodynamic coupling phenomenon when the interface between iron ore and carbon separates. ${ }^{5,6}$ On the other hand, the mechanical milling can make a strong contact between iron ore and carbon, ${ }^{4)}$ and the reaction temperature can decrease 
significantly. However, the actual burdens such as iron ore and coke contain many kinds of mineral matter and ash which might disturb the grindability of milling operation and the contacting state between iron oxide and carbon.

In this paper, the effects of oxides and carbonate additions $\left(\mathrm{Al}_{2} \mathrm{O}_{3}, \mathrm{SiO}_{2}\right.$ and $\left.\mathrm{CaCO}_{3}\right)$ were investigated for the fundamental study of the actual influence of the gangue of iron ore and the ash of coke.

\section{Experimental}

Figure 2 illustrates the sample preparation and addition of oxides and carbonate in this experiment. The milling device is the planetary ball mill, in which the movements consist of the revolution and the rotation (Fritsch Pulverisette 6 planetary ball mill). A ceramics (alumina) vessel of 500 $\mathrm{cm}^{3}$ volume and 10 alumina balls with $20 \mathrm{~mm}$ in diameter were used in this experiment. The rotating speed was maintained constant at $200 \mathrm{rpm}$. The weight ratio of powder to balls was 1:5.

The starting materials of graphite and hematite for milling were prepared as follows. The graphite was crushed into a powder $(75-500 \mu \mathrm{m})$ roughly from the electrode material with a high purity (ash $<100 \mathrm{ppm})$ and high density $(1.77$

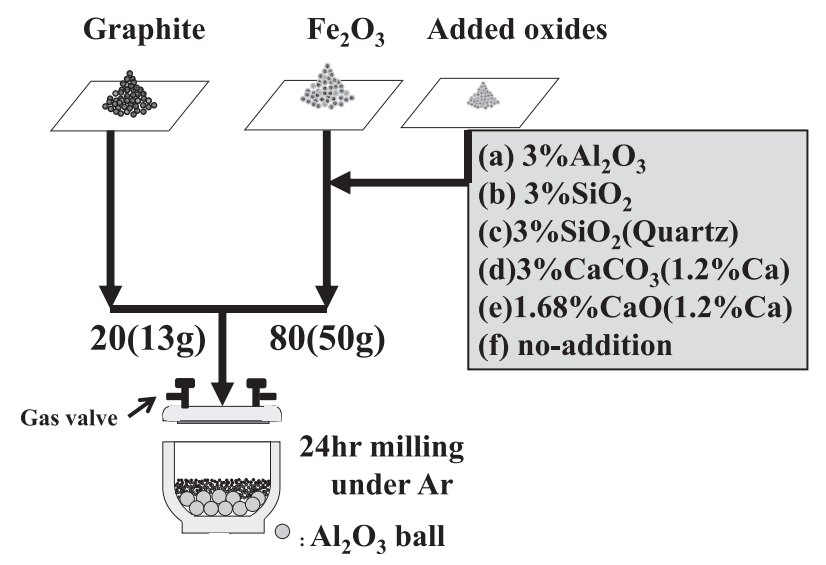

Fig. 2. Sample preparation for the mechanical milling. $\left.\mathrm{g} / \mathrm{cm}^{3}\right)$. Reagent grade of hematite $\left(>99 \% \mathrm{Fe}_{2} \mathrm{O}_{3}\right)$ was pressed into a tablet $(20 \mathrm{~mm} \phi \times 4 \mathrm{~mm}$ height $)$ with 19.6 MPa $\left(200 \mathrm{kgf} / \mathrm{cm}^{2}\right)$. Then, the tablet was sintered at $1000^{\circ} \mathrm{C}$ for $24 \mathrm{~h}$ under an air atmosphere. Finally, the sintered tablet was crushed into the same size as the graphite powder (75$500 \mu \mathrm{m})$.

The added oxides and carbonate samples are
(a) 3 mass $\% \mathrm{Al}_{2} \mathrm{O}_{3}$ (reagent grade)
(b) 3 mass $\% \mathrm{SiO}_{2}$ (reagent grade)
(c) 3 mass $\% \mathrm{SiO}_{2}$ (Quartz)
(d) 3 mass $\% \mathrm{CaCO}_{3}$ (reagent grade),
(e) $1.68 \% \mathrm{CaO}$
(f) $0 \%$ (non-addition).

The amount of addition was basically 3 mass $\%$ in the total sample. The quartz was prepared for the sake of comparison with $\mathrm{SiO}_{2}$ (reagent grade) using a transparent quartz tube which was crushed and sieved into $-500 \mu \mathrm{m}$. The $\mathrm{CaO}$ was prepared from $\mathrm{CaCO}_{3}$ which was decomposed at $800^{\circ} \mathrm{C}$ under air atmosphere, and 1.68 mass $\% \mathrm{CaO}$ was added so as to fix the $\mathrm{Ca}$ content $(1.2 \% \mathrm{Ca})$. Those oxides and carbonate were once added to hematite sample and ground with an alumina mortar and pestle for about 1 minute.

The ratio of hematite to graphite for the milling was 80:20 which was $50 \mathrm{~g}$ hematite includes additives and was $13 \mathrm{~g}$ graphite. This ratio and total volume of sample are important to get the uniform result among the different runs. In this paper, the results at $24 \mathrm{~h}$ milling were discussed.

The graphite weight was decided based on Eq. (1), and increased to $5 \%$.

$$
\mathrm{Fe}_{2} \mathrm{O}_{3}+3 \mathrm{C}=2 \mathrm{Fe}+3 \mathrm{CO} .
$$

Figure 3 shows SEM images of added oxides and carbonate before milling. $\mathrm{CaCO}_{3}$ is about $10 \mu \mathrm{m}$ aggregated particle which consisted of $1-2 \mu \mathrm{m}$ rectangular and smaller particles. $\mathrm{SiO}_{2}$ consists of a broken and nonuniform particles whose particle size is from $10 \mu \mathrm{m}$ to sub-micron. $\mathrm{Al}_{2} \mathrm{O}_{3}$ is a dense and 1-2 $\mu \mathrm{m}$ particle which is aggregated in about $50 \mu \mathrm{m}$. These samples were weighed out $3 \mathrm{mass} \%$ to the total mixture, and then, mixed with hematite and graphite. Although the samples after milling were observed using SEM, the added sample in the hematite and graphite could

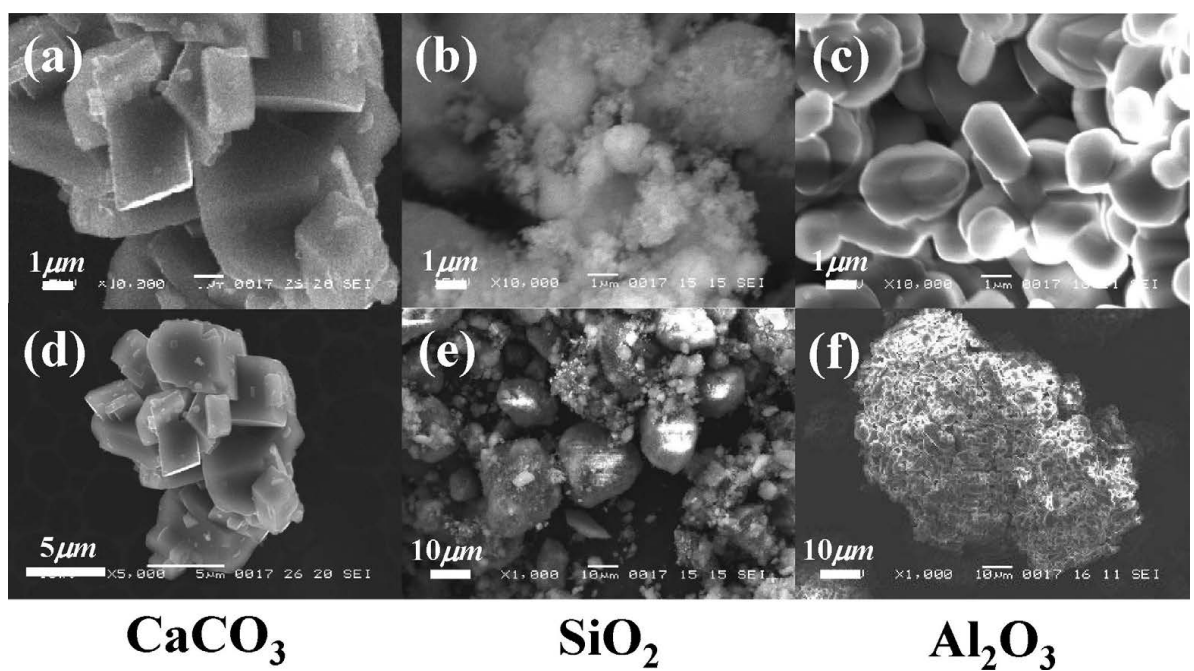

Fig. 3. SEM images of oxides and carbonate added to the milling sample. 
not distinguish because the apparent shape after milling was almost the same.

Figure 4 shows the gas analysis system for determining the gas composition evolved during the milling. The milling vessel is made of alumina and has a gas tight cap having gas inlet and outlet valves. The samples (hematite, graphite and additives) were put into the vessel, and the vessel was evacuated for the leak test. After a given time, the vessel was substituted for an argon and milling was carried out for a given time.

After milling, the vessel was taken out from the milling device and was set on the gas analysis system as shown in Fig. 4. Before the gas analysis in the vessel was performed, the remained air in the tubing system was evacuated and substituted for an argon. Then, $200 \mathrm{Ncc} / \mathrm{min}$ argon was flowed in the by-pass and the leak valve of QMS (Quadrupole Mass Spectrometer) was opened for starting the gas analysis. When the output signal from QMS became stable, the valves of the vessel were opened simultaneously and the bypass was closed. These sequences were the procedure of the gas analysis for the evolved gas during the milling.

On the other hand, the reactivity of the milled sample was examined using TG-DTA-MS (Fig. 5). The heating up condition was programmed for $10^{\circ} \mathrm{C} / \mathrm{min}$ until $1100^{\circ} \mathrm{C}$ and 30 min hold at $1100^{\circ} \mathrm{C}$. The atmosphere was an argon with high purity ( $>99.999 \%)$. The weight of sample mixture was about $17 \mathrm{mg}$ and the measuring crucible was platinum with $5 \mathrm{~mm} \phi$ in diameter.

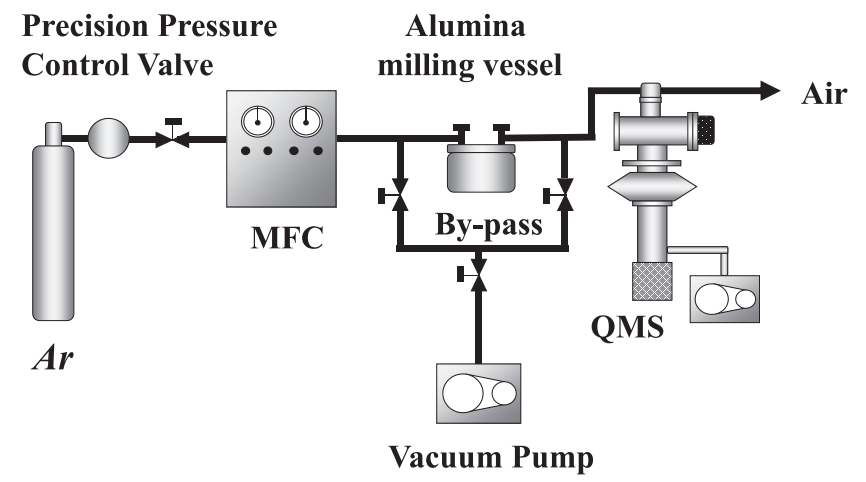

Fig. 4. Gas analysis system in the vessel after milling.

\section{Results and Discussions}

\section{1. 'no-addition' (Hematite-graphite Mixture for Comparison)}

'no-addition' means the hematite-graphite mixture for comparison and the result is shown in Fig. 6. RTG means the rate of weight loss obtained from the differentiation of the weight loss curve of TG (thermal gravimetry).

The definitions of RTG and TG are as follows:

$$
\begin{gathered}
\operatorname{TG}(\%)=\frac{\Delta W}{\left([O]_{0}+[C]_{0}\right)} \times 100 \\
\operatorname{RTG}(\% / \mathrm{min})=\frac{d T G(\%)}{d t} .
\end{gathered}
$$

where $\Delta W$ : weight change of sample $(g)\left(=W_{t+1}-W_{t}\right)$

$W_{t}$ : weight of reducible oxygen and fixed carbon $(g)$ at time $t,\left(=[O]_{t}+[C]_{t}\right)$

$[O]_{0}$ : reducible oxygen $(g)$

$$
\begin{aligned}
& \left(=\left(\mathrm{W}_{\mathrm{Fe} 2 \mathrm{O3}}\right) \times 16 \times 3 /(55.847 \times 2+16 \times 3)\right. \\
& {[C]_{0}: \text { fixed carbon }(\mathrm{g})\left(=W_{\text {graphite }}\right)}
\end{aligned}
$$

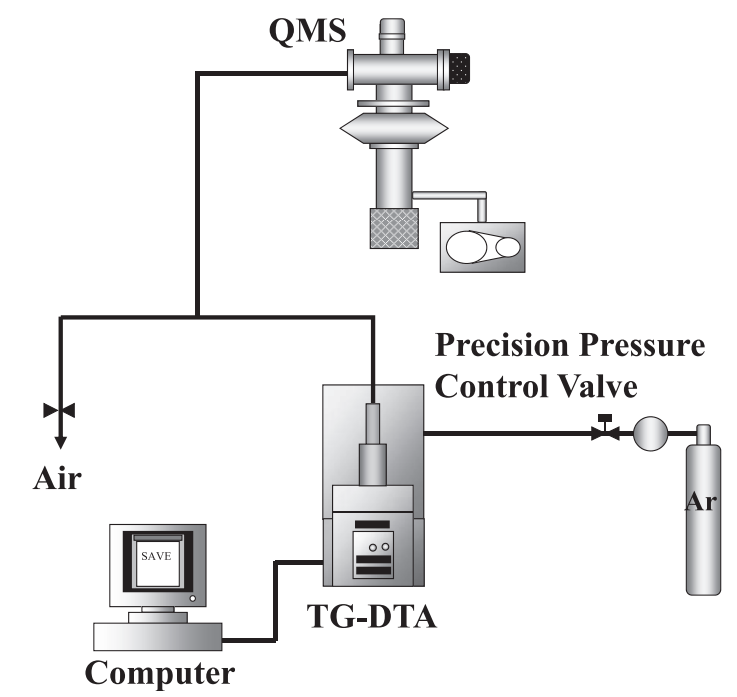

Fig. 5. TG-DTA-MS measurement for determining the reactivity of sample after milling (Ar atmosphere. Heating rate: $10^{\circ} \mathrm{C} / \mathrm{min}$, $30 \mathrm{~min}$. hold at $1100^{\circ} \mathrm{C}$ ).

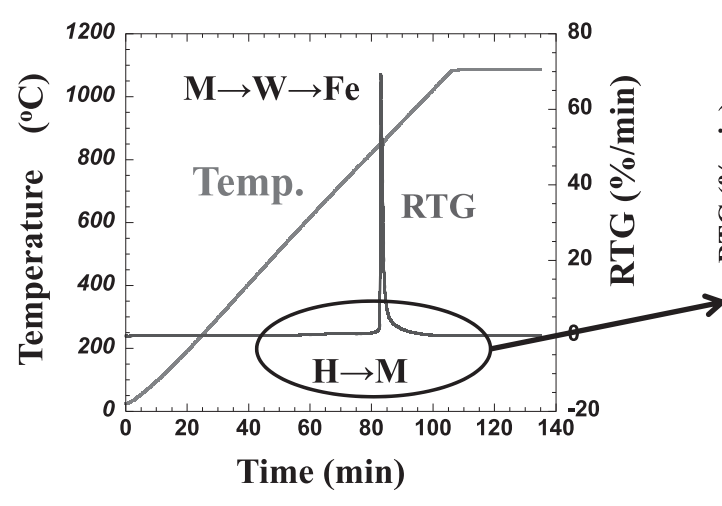

(a)

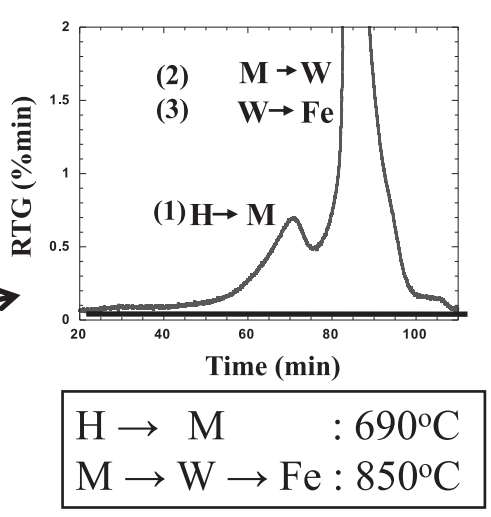

(b)

Fig. 6. Result of $\mathrm{TG}$ measurement of no-addition sample $\left(\mathrm{Fe}_{2} \mathrm{O}_{3}+\mathrm{C}\right)$ after mechanical milling. 
The RTG profile shows the very narrow width and spike like shape, which means the quite rapid reaction rate. ${ }^{1)}$ Apparently the reaction seems a single step reaction. However, when the background was magnified, another curve appeared as shown in Fig. 6(b). From the analysis of the reaction degree on the $\mathrm{TG}$ curve, it was found that the small curve corresponded to the hematite-magnetite reduction $(\mathrm{H}-$ $\mathrm{M})$. The main peak (largest one) corresponded to the magnetite-wustite-iron reduction $(\mathrm{M}-\mathrm{W}-\mathrm{Fe}){ }^{1)}$

$$
\begin{array}{r}
\mathrm{H} \rightarrow \mathrm{M}: \mathrm{Fe}_{2} \mathrm{O}_{3}+1 / 3 \mathrm{C}=2 / 3 \mathrm{Fe}_{3} \mathrm{O}_{4}+1 / 3 \mathrm{CO} . \\
\mathrm{M} \rightarrow \mathrm{W}: 2 / 3 \mathrm{Fe}_{3} \mathrm{O}_{4}+2 / 3 \mathrm{C}=2 \mathrm{FeO}+2 / 3 \mathrm{CO} . \\
\quad \mathrm{W} \rightarrow \mathrm{Fe}: 2 \mathrm{FeO}+2 \mathrm{C}=2 \mathrm{Fe}+2 \mathrm{CO} \ldots \ldots \ldots . . .
\end{array}
$$

(in this paper, $\mathrm{Fe}_{\mathrm{t}} \mathrm{O}$ was expressed as $\mathrm{FeO}$ in order to convenience)

There is a possibility of the reaction that the $\mathrm{CO}_{2}$ is produced especially in the lower temperature range. However, since the mechanism is not clear at this moment, the commonly accepted reactions were listed from Eqs. (4) to (6) in this experiment.

The temperature of $\mathrm{H}-\mathrm{M}$ reaction was $690^{\circ} \mathrm{C}$ and $\mathrm{M}-\mathrm{W}-$ $\mathrm{Fe}$ was $840^{\circ} \mathrm{C}$. The hematite reduction is $11 \%$ for total reduction. As the remained $\mathrm{M}-\mathrm{W}-\mathrm{Fe}$ reduction was $89 \%$ and this reduction occurred at $850^{\circ} \mathrm{C}$ drastically. In this study, according to the comparison with the result of 'noaddition', the effects of oxides and carbonate addition on the reactivity were discussed.

\subsection{Gas Evolution during Milling}

The gas evolution phenomenon has been studied in the previous study. ${ }^{2}$ It was found that the most of evolved gas was $\mathrm{CO}$ which came from the adsorbed oxygen on the sur-

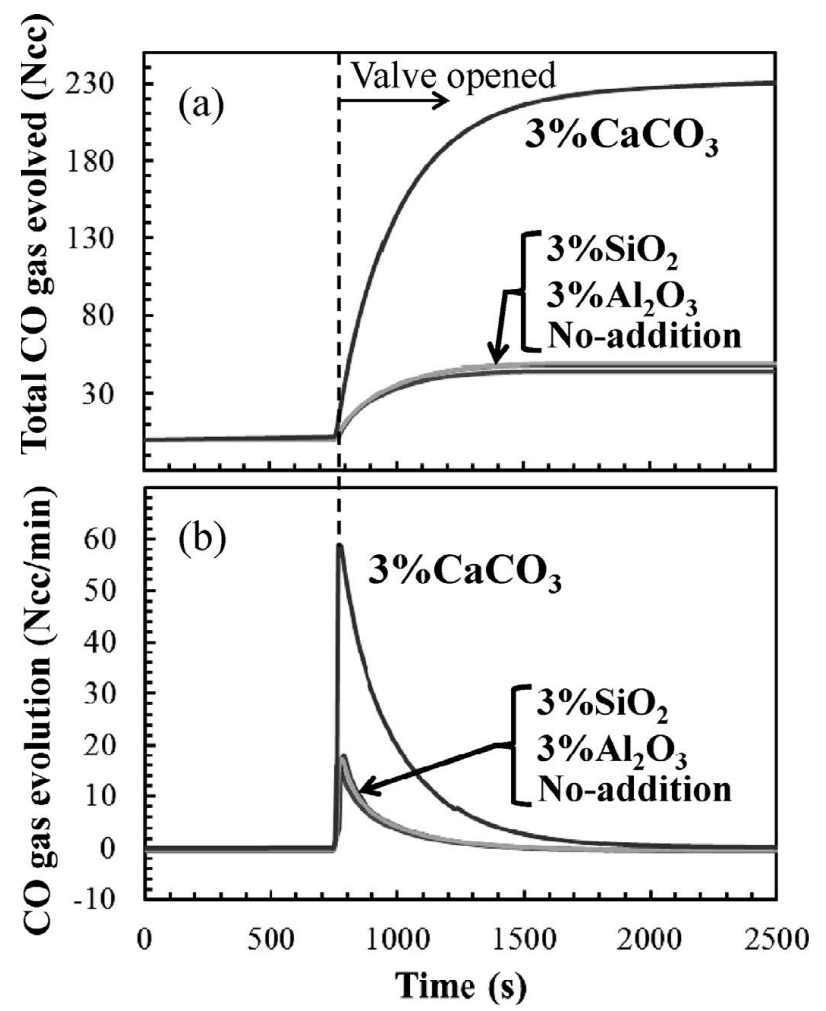

Fig. 7. Result of gas analysis in the milling vessel after milling operation. face of carbon. From the difference of total gas evolved, the milling of the hematite and carbon mixture showed a larger gas evolution which meant the existence of reduction reaction during milling. In this study, using the same method, the gas evolution was analyzed and the results were plotted on Fig. 7. When the valves on the cap of vessel were open, the gas in the vessel was exhausted to the argon flow and could be analyzed by QMS. Figure 7(a) and Table 1 show the total gas (CO) evolution (Ncc) and Fig. 7(b) shows the rate of gas evolution ( $\mathrm{Ncc} / \mathrm{min})$. The total $\mathrm{CO}$ gases for the samples of $\mathrm{Al}_{2} \mathrm{O}_{3}, \mathrm{SiO}_{2}$ and no-addition were almost the same and were about $50 \mathrm{Ncc}$. On the other hand, the evolved gas of $\mathrm{CaCO}_{3}$ addition was the largest and $230 \mathrm{Ncc}$. The difference of gas was $180 \mathrm{Ncc}$. Since $\mathrm{CO}_{2}$ gas did not detected, All gas was $\mathrm{CO}$, and the decomposition reaction of calcium carbonate $\left(\mathrm{CaCO}_{3} \rightarrow \mathrm{CaO}+\mathrm{CO}_{2(g)}\right)$ does not need to take into account. Gibb's free energies of the possible reactions are calculated and shown in Fig. 8. ${ }^{7)}$

$$
\begin{gathered}
\left(\mathrm{CaCO}_{3} \rightarrow \mathrm{CaO}_{2}+\mathrm{CO}_{(g)}\right) \\
\left(\mathrm{CaO}_{2}+\mathrm{C} \rightarrow \mathrm{CaO}+\mathrm{CO}_{(g)}\right) \\
\left(\mathrm{CaCO}_{3}+\mathrm{C} \rightarrow \mathrm{CaO}+2 \mathrm{CO}_{(g)}\right)
\end{gathered}
$$

The reaction (7) is thermodynamically impossible reaction. However, the milling of $\mathrm{CaCO}_{3}$ can form a $\mathrm{CaO}_{2}$, which is unstable substance and an intense oxidative one. The reagent $\mathrm{CaCO}_{3}$ was alone milled and examined by XRD. Figure 9 shows the results of XRD of $\mathrm{CaCO}_{3}$ after milling in comparison with $\mathrm{CaO}$ and $\mathrm{CaCO}_{3}$ without milling. A small quantity of $\mathrm{CaO}_{2}$ was observed among the broad $\mathrm{CaCO}_{3}$ peaks, but the existence of $\mathrm{CaO}$ could not con-

Table 1. Content of oxides and carbonate added and results of obtained.

\begin{tabular}{lcccc}
\hline \multicolumn{1}{c}{$\begin{array}{c}\text { Added } \\
\text { material }\end{array}$} & $\begin{array}{c}\text { Content } \\
\text { (mass\%) }\end{array}$ & $\begin{array}{c}\text { Evolved gas } \\
\text { during } \\
\text { milling }\end{array}$ & $\begin{array}{c}\text { Temp. of peak } \\
\text { at M-W-Fe } \\
\text { reaction }\end{array}$ & $\begin{array}{c}\Delta \text { T from } \\
\text { the peak of } \\
\text { no-addition }\end{array}$ \\
\hline $\mathrm{CaCO}_{3}$ (reagent) & 3 & $230 \mathrm{Ncc}$ & $790^{\circ} \mathrm{C}$ & -60 \\
$\mathrm{CaO}$ (calcined from $\mathrm{CaCO}_{3}$ ) & 1.68 & Not measured & $860^{\circ} \mathrm{C}$ & 10 \\
$\mathrm{SiO}_{2}$ (reagent) & $3 \%$ & $50 \mathrm{Ncc}$ & $1000^{\circ} \mathrm{C}$ & 150 \\
$\mathrm{SiO}_{2}$ (quartz) & $3 \%$ & Not measured & $900^{\circ} \mathrm{C}$ & 50 \\
$\mathrm{Al}_{2} \mathrm{O}_{3}$ (reagent) & $3 \%$ & $48 \mathrm{Ncc}$ & $850^{\circ} \mathrm{C}$ & 0 \\
$\mathrm{No}^{-a d d i t i o n}$ & $0 \%$ & $49 \mathrm{Ncc}$ & $850^{\circ} \mathrm{C}$ & 0 \\
\hline
\end{tabular}

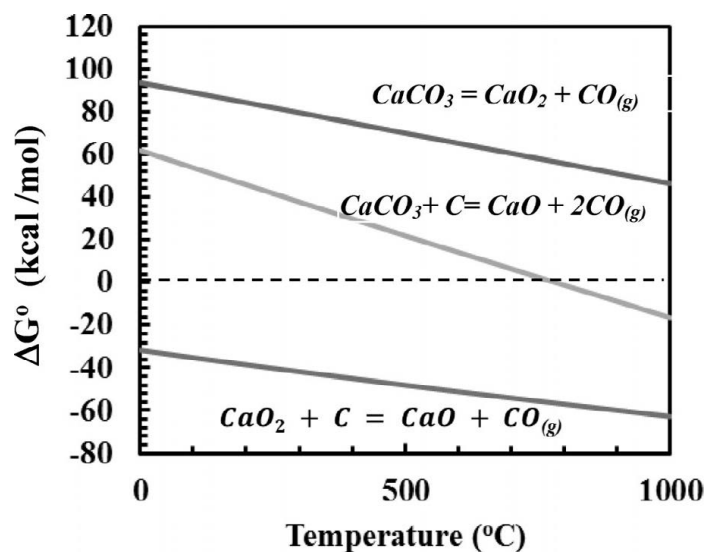

Fig. 8. Comparison of $\Delta \mathrm{G}^{\circ}$ of the $\mathrm{CaCO}_{3}$ related reactions 
firmed. In the case of milling of mixture consisted of $\mathrm{Fe}_{2} \mathrm{O}_{3}$, $\mathrm{C}$ and $\mathrm{CaCO}_{3}, \mathrm{CaO}_{2}$ might react with $\mathrm{C}$, which is the reaction (8), as soon as the reaction (7) occurred. The overall reaction can be expressed by the reaction (9).

The evolved gas for $\mathrm{CaCO}_{3}$ addition was about $180 \mathrm{Ncc}$ in Fig. 7. The weight of $\mathrm{CaCO}_{3}$ relating to the $\mathrm{CO}$ gas evolution can be calculated as $0.4 \mathrm{~g}$ based on the Eq. (9). As the initial weight of the added $\mathrm{CaCO}_{3}$ was $1.5 \mathrm{~g}$, it was considered that $27 \%$ of $\mathrm{CaCO}_{3}$ would react during the milling. Although the extent of reduction reaction of hematite by $\mathrm{CO}$ gas evolved is unknown, the percentage would be small. Even if the all of CO gas $(180 \mathrm{Ncc})$ was used for the reduction, the reduction degree was only $3 \%$ in maximum.

\subsection{Effect of Oxides and Carbonate Addition on the Reaction Rate during Heating Up Experiment}

Figure 10 shows the results of 3 mass $\%$ of $\mathrm{Al}_{2} \mathrm{O}_{3}, \mathrm{SiO}_{2}$ and $\mathrm{CaCO}_{3}$ addition in comparison with the hematite-graph-

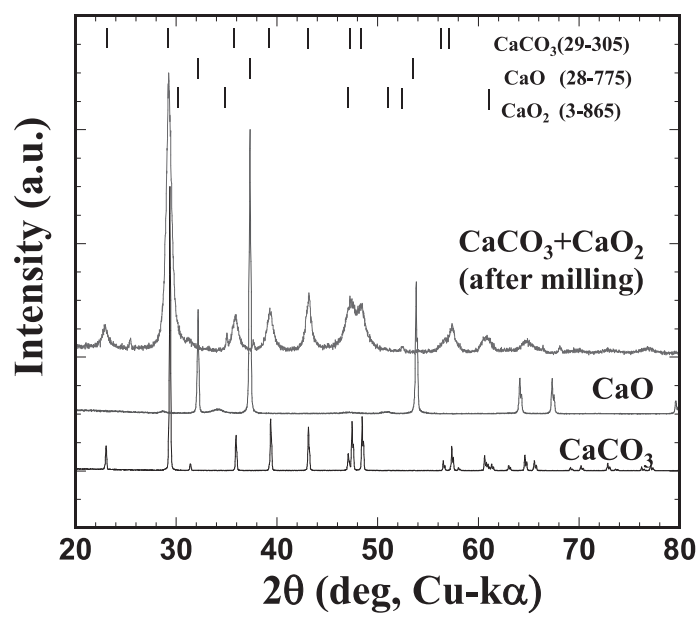

Fig. 9. Results of $\mathrm{XRD}$ analysis of $\mathrm{CaCO}_{3}$ after milling in comparison with $\mathrm{CaO}$ and reagent $\mathrm{CaCO}_{3}$.

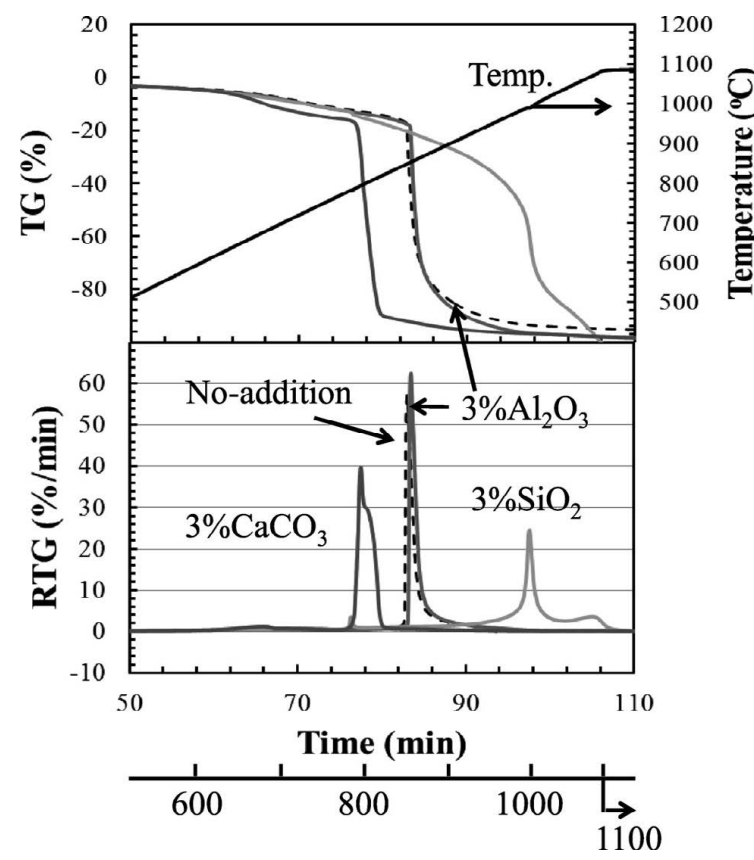

Fig. 10. Comparison of reaction rate (RTG) and weight loss (TG) among no-addition, $\mathrm{SiO}_{2}$ (reagent), $\mathrm{Al}_{2} \mathrm{O}_{3}$ and $\mathrm{CaCO}_{3}$. ite mixture (no-addition). All samples were milled for $24 \mathrm{~h}$ under an argon atmosphere. The milled samples were served for the TG-DTA-MS measurement (Fig. 5) and the reaction profiles were obtained (Fig. 10). It was found that $\mathrm{Al}_{2} \mathrm{O}_{3}$ has no effect on the reaction rate, because the main reaction curve was overlapped with that of 'no-addition', completely. It could be understood that as the vessel and balls for milling are made of alumina, the effect of alumina might already exist. It is concluded that the effect of alumina was negligible in the range of alumina content in this experiment. If another kind of material for the milling vessel was adopted, the effects of alumina could become clearer than the present one.

The addition of $\mathrm{CaCO}_{3}$ decreased the reaction temperature which meant the acceleration effect on the reaction between hematite and carbon. The details were discussed in the later section.

$\mathrm{SiO}_{2}$ showed the retardation effect. Both of $\mathrm{H}-\mathrm{M}$ and $\mathrm{M}-$ $\mathrm{W}-\mathrm{Fe}$ reactions moved toward the high temperature regions. $\mathrm{H}-\mathrm{M}$ reaction was $700^{\circ} \mathrm{C}$ and $\mathrm{M}-\mathrm{W}-\mathrm{Fe}$ reaction was $1000^{\circ} \mathrm{C}$, which were $10^{\circ} \mathrm{C}$ and $150^{\circ} \mathrm{C}$ higher than that of 'no-addition', respectively. About 10\% remained reduction occurred at $1080^{\circ} \mathrm{C}$ and this behavior of reaction was typical to the $\mathrm{SiO}_{2}$ addition. The $\mathrm{SiO}_{2}$ used in this experiment was reagent grade as mentioned above. This type of $\mathrm{SiO}_{2}$ has a nature of sticking on the surface of hematite. It could be considered that the existence of $\mathrm{SiO}_{2}$ inhibited from the contact between carbon and hematite.

To clarify the effect of reagent $\mathrm{SiO}_{2}$, a quartz was used for the additives. A transparent quartz tube was crashed and sieved into $-500 \mu \mathrm{m}$. The result was shown in Fig. 11 in comparison with the results of no-addition and reagent $\mathrm{SiO}_{2}$.

The main peak of RTG of quartz was also separated into two peaks, $900^{\circ} \mathrm{C}$ and $920^{\circ} \mathrm{C}$, while the peaks of the reagent $\mathrm{SiO}_{2}$ were at $1000^{\circ} \mathrm{C}$ and $1080^{\circ} \mathrm{C}$. It was found that the

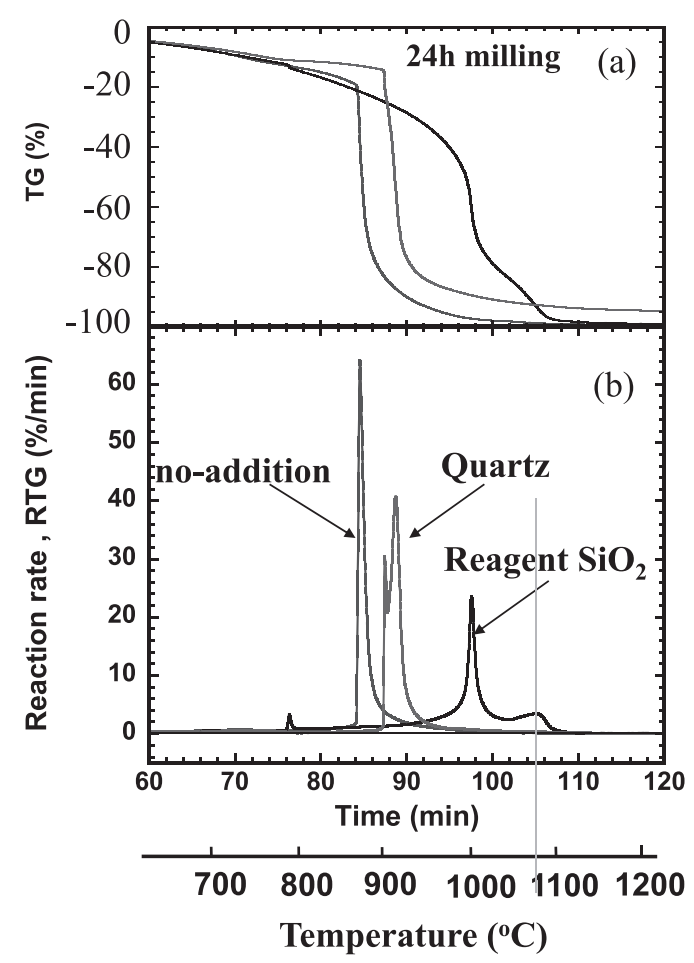

Fig. 11. Comparison of reaction rate (RTG) and weight loss (TG) among no-addition, $\mathrm{SiO}_{2}$ (reagent) and Quartz. 
retardation effect of quartz was smaller than that of reagent $\mathrm{SiO}_{2}$. This retardation mechanism was related a block effect on the contact between hematite and carbon. In the case of reagent $\mathrm{SiO}_{2}$, an adhesion of $\mathrm{SiO}_{2}$ to hematite is significant comparing to quartz. When the hematite particles are covered by $\mathrm{SiO}_{2}$, the contact between hematite and carbon would be disturbed. Only the increasing temperature can modify the poor contact between hematite and carbon. In addition, the two separated peaks of RTG mean the different distance caused by the $\mathrm{SiO}_{2}$ adhesion. On the other hand, adhesion effect of quartz is lower than that of reagent $\mathrm{SiO}_{2}$, and the particle size of quartz are larger than that of reagent $\mathrm{SiO}_{2}$. From these reasons, the peaks of quartz located between no-addition and reagent $\mathrm{SiO}_{2}$. These mechanisms summarized and illustrated in the later section.

Figure 12 shows the comparison of RTG and TG between $\mathrm{CaCO}_{3}$ and $\mathrm{CaO}$. In this case, the content of $\mathrm{CaCO}_{3}$ was 3 mass $\%$ and $\mathrm{CaO}$ was 1.68 mass $\%$, in which the content of $\mathrm{Ca}$ was the same and $1.2 \mathrm{mass} \% \mathrm{Ca}$. Since there was some possibility of a catalysis effect of $\mathrm{Ca}$ on the gasification reaction, the content of cation was unified in the present experiment. $\mathrm{CaO}$ was made through the decomposition of $\mathrm{CaCO}_{3}$ under an air atmosphere. The $\mathrm{CaO}$ obtained was examined by XRD and shown in Fig. 9. In Fig. 12, the main peak of $\mathrm{CaO}$ addition was $860^{\circ} \mathrm{C}$ which was $10^{\circ} \mathrm{C}$ higher than that of no-addition. It was found that the $\mathrm{CaO}$ did not have an acceleration effect on the reaction, and $\mathrm{CaCO}_{3}$ alone had an acceleration effect. As mentioned above, the formation of $\mathrm{CaO}_{2}$ during the milling should have an acceleration effect on the gasification as shown by Eq. (8). In the case of heating up condition, the remained $\mathrm{CaCO}_{3}$ will decomposed around $800^{\circ} \mathrm{C}$ as expressed by Eq. (10).

$$
\left(\mathrm{CaCO}_{3} \rightarrow \mathrm{CaO}+\mathrm{CO}_{2(g)}\right)
$$

Then, the decomposed $\mathrm{CO}_{2}$ gas will react with carbon as expressed by Eq. (11),

$$
\left(\mathrm{CO}_{2}+\mathrm{C} \rightarrow 2 \mathrm{CO}_{(g)}\right)
$$

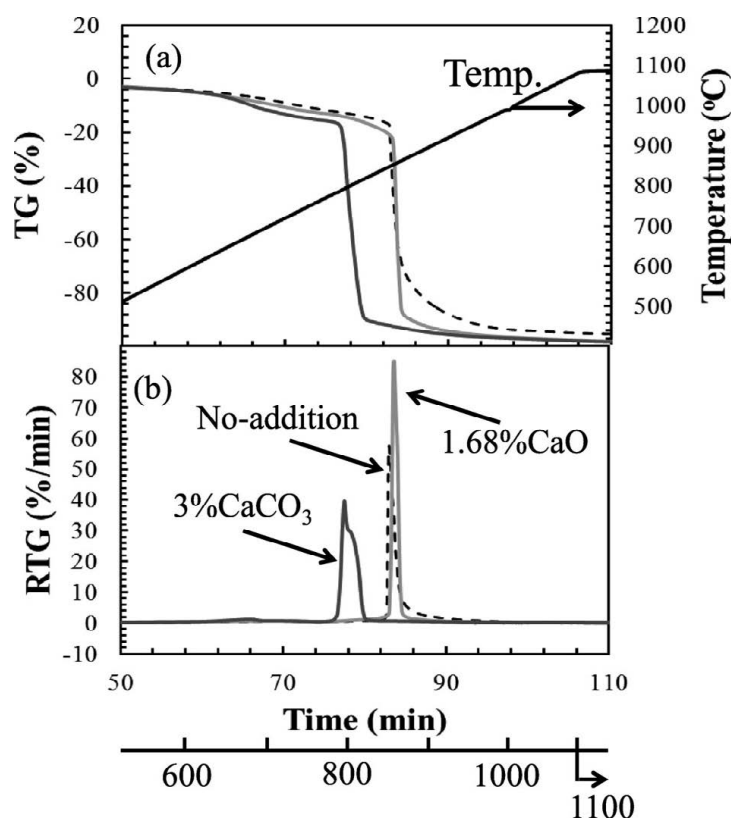

Fig. 12. Comparison of reaction rate (RTG) and weight loss (TG) among no-addition, $\mathrm{CaCO}_{3}$ (reagent) and $\mathrm{CaO}$.
From this mechanism, it was considered that the reduction reactions by CO gas (Eqs. (12)-(14)) promoted and the main peak of RTG of $\mathrm{CaCO}_{3}$ addition existed at around $800^{\circ} \mathrm{C}$.

$$
\begin{gathered}
\mathrm{Fe}_{2} \mathrm{O}_{3}+1 / 3 \mathrm{CO}=2 / 3 \mathrm{Fe}_{3} \mathrm{O}_{4}+1 / 3 \mathrm{CO}_{2} \\
2 / 3 \mathrm{Fe}_{3} \mathrm{O}_{4}+2 / 3 \mathrm{CO}=2 \mathrm{FeO}+2 / 3 \mathrm{CO}_{2} \\
2 \mathrm{FeO}+2 \mathrm{CO}=2 \mathrm{Fe}+2 \mathrm{CO}_{2} \ldots \ldots . . .
\end{gathered}
$$

$\mathrm{CaCO}_{3}$ shows the acceleration effect on the reaction. The $\mathrm{H}-\mathrm{M}$ reaction was $660^{\circ} \mathrm{C}$ and the $\mathrm{M}-\mathrm{W}-\mathrm{Fe}$ reaction was $790^{\circ} \mathrm{C}$, and those were $40^{\circ} \mathrm{C}$ and $60^{\circ} \mathrm{C}$ lower, respectively, than that of 'no-addition' (Table 1). The temperature changes of RTG peak obtained in this experiment are summarized in Fig. 13. It was found that the most of oxides selected in this experiment had a retardation effect on the reaction between hematite and carbon and only $\mathrm{CaCO}_{3}$ had an acceleration effect.

The detail of acceleration mechanism $\mathrm{CaCO}_{3}$ was investigated in the successive experiments, where the methods of $\mathrm{CaO}$ addition were changed. The results will be published elsewhere.

The mechanism of retardation effects of $\mathrm{SiO}_{2}$ on the reaction between hematite and carbon was illustrated in Fig. 14.

In the case of $\mathrm{CaCO}_{3}$, the acceleration mechanisms are considered as shown in Fig. 14. During milling operation, milling energy decomposes the $\mathrm{CaCO}_{3}$ and makes an active $\mathrm{CaO}_{2}$ which react with carbon. In this step, the reduction

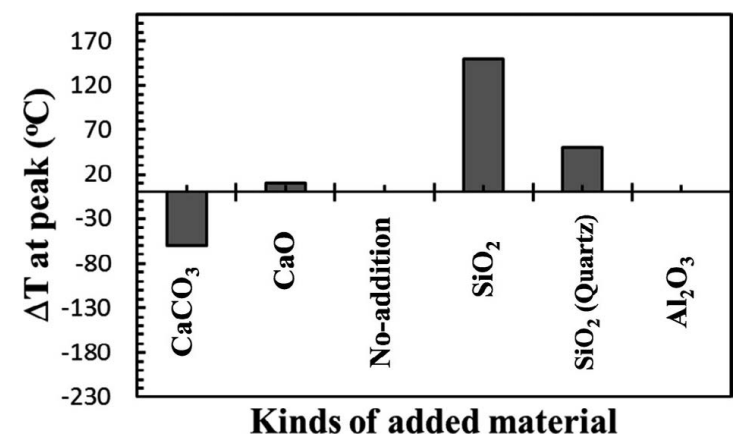

Fig. 13. Change of Temperature at main peak of reaction from the one of no-addition sample.

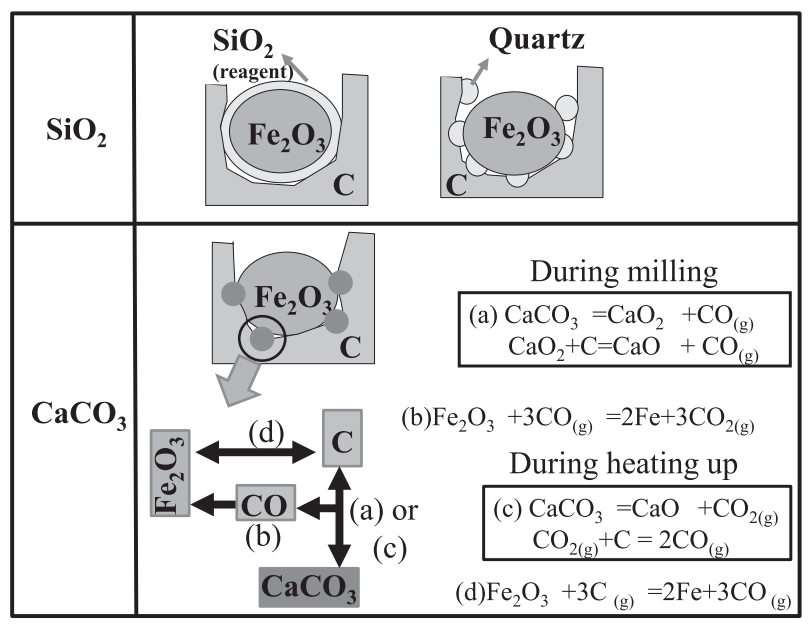

Fig. 14. Possible mechanism of acceleration of $\mathrm{CaCO}_{3}$ and retardation of $\mathrm{SiO}_{2}$ on the reaction rate of mixture (hematite and carbon). 
reaction would not be dominant. During heating up experiment, the decomposition of $\mathrm{CaCO}_{3}$ becomes dominant around $800^{\circ} \mathrm{C}$ and the gasification reaction by evolved $\mathrm{CO}_{2}$ gas produces $\mathrm{CO}$ gas which enhances the reduction reaction of hematite.

\section{Conclusions}

3 mass $\% \mathrm{CaCO}_{3}, \mathrm{SiO}_{2}$, and $\mathrm{Al}_{2} \mathrm{O}_{3}$ were added to hematitegraphite mixture respectively and the milling was carried out for $24 \mathrm{~h}$. To clarify the effect on the reaction rate, TG-DTA analysis was carried out with a heating up condition $\left(10^{\circ} \mathrm{C} /\right.$ min, 30 min hold at $1100^{\circ} \mathrm{C}$ ) under an argon atmosphere. The obtained results are as follows:

(1) 3 mass $\% \mathrm{CaCO}_{3}$ addition enhances the reaction between hematite and carbon, and the temperature of peak of RTG curve was $790^{\circ} \mathrm{C}$, which was $60^{\circ} \mathrm{C}$ lower than that of no-addition.

(2) Inversely, 3 mass $\% \mathrm{SiO}_{2}$ addition retarded the reaction, and the temperature of peak was $1000^{\circ} \mathrm{C}$. On the other hand, 3 mass $\%$ quartz had lower retardation effect and the peak temperature was $900^{\circ} \mathrm{C}$.

(3) 3 mass $\% \quad \mathrm{Al}_{2} \mathrm{O}_{3}$ addition showed no effect on the reaction.

(4) It was found that the gas evolution during milling was not $\mathrm{CO}_{2}$, but $\mathrm{CO}$. Taking into account the result of $\mathrm{XRD}$, the reaction occurring during milling of $\mathrm{CaCO}_{3}$ was as follows:

$$
\begin{aligned}
& \mathrm{CaCO}_{3}=\mathrm{CaO}_{2}+\mathrm{CO}_{(g)} \\
& \mathrm{CaO}_{2}+\mathrm{C}=\mathrm{CaO}+\mathrm{CO}_{(g)}
\end{aligned}
$$

\section{REFERENCES}

1) J. Vahdati Khaki, Y. Kashiwaya, Y. Suzuki and K. Ishii: ISIJ Int., 42 (2002), 13.

2) Y. Kashiwaya, H. Suzuki and K. Ishii: ISIJ Int., 44, (2004), 1970.

3) Y. Kashiwaya, H. Suzuki and K. Ishii: ISIJ Int., 44, (2004), 1975.

4) Y. Kashiwaya and K. Ishii: ISIJ Int., 44, (2004), 1981.

5) Y. Kashiwaya, M. Kanbe and K. Ishii: ISIJ Int., 41 (2001), 818.

6) Y. Kashiwaya, M. Kanbe and K. Ishii: ISIJ Int., 46, (2006), 1610.

7) HSC Thermochemical Database, ver.5.1, OUTTEC, Finland, (2005) 